1932

\title{
The treatment of lobar pneumonia
}

Harley S. Eklund

University of Nebraska Medical Center

This manuscript is historical in nature and may not reflect current medical research and practice. Search PubMed for current research.

Follow this and additional works at: https://digitalcommons.unmc.edu/mdtheses

Part of the Medical Education Commons

\section{Recommended Citation}

Eklund, Harley S., "The treatment of lobar pneumonia" (1932). MD Theses. 197.

https://digitalcommons.unmc.edu/mdtheses/197

This Thesis is brought to you for free and open access by the Special Collections at DigitalCommons@UNMC. It has been accepted for inclusion in MD Theses by an authorized administrator of DigitalCommons@UNMC. For more information, please contact digitalcommons@unmc.edu. 
The Treatment of Lobar Pneumonia

by

Harley S. Eklund.

$14 \%$ 


\section{Preface}

Pneumonia is probably one of the most frequent diseases With which the average physician has to deal. The disease differs from many otherg in that it $1 \mathrm{~s}$ so common and algo that Its eymptoms are quite commonly known among laymen. There fore, it behooves the doctor, who is called to see a case, to not only be able to recognize the digeage but to have at his command therapeutic measures which may bring about a cure of the patient.

Hundreds of different therapeutic measures heve been used againgt the disease and probably no two physlcians treat the disease precisely the same. Therefore, to one who is entering into the practice of medicine and to one who has had no personal patients upon whom to exercise his knowledge, it becomes a most dificult problem. Consequently, may the preceeding pages cast some light upon the past and present status of the treatment of pneumonia, so that a few general facts may be made a foundation upon which the new physician can institute a treatment which will better his individual patient.

It was my ambition in reviewing the literature to find some experimental evidence upon which the now important therapeutic measures are used. Also, to pring forth such laboratory and clinical data as seem necessary to impress the reader. 


\section{History}

Pneumonia is by no means a modern disease. It was recognized by the ancients. According to Howard, (1), the firet account was given in the Works of Hippocrates ( $460-370$ B.C.), However, it was confused with pleuritis and was called peripneumony. This was disputed by Sprengel who claimed that pleurisy and pneumonia were separate diseaseg in that pleuritis was an Inflamation of the costal pleura while pneumonia was a congestion of the blood vessels of the lung.

Osler, (2), in his textbook quotes Aretaeus' remarkable description, in the first or second century of the christian era, of the clinical picture of pneumonia. In his description of the symptoms, which were so accurate that even a layman might recognize the disease, he remarks that the cough is dry and may bring up blood tinged sputum. He was the first to describe the blood tinged character of the sputum.

Conrad, (3), found that there was an attempt at distinction between pleuritis and pneumonia down to the time of sydenham (1695) Whose view was generally accepted. Sydenham sald; "Having thoroughly considered it only a fever occasioned by a peculiar inflammation of the blood whereby nature throws off the peccant matter upon the pleura, and sometimes upon the Iungs whence a peripneumony arises which in my opinion only differg from pleur$i s y$ in degree and in regpect of the great violence, and the larger extent of the same cause." Wallis in his edition of sydenham vrites: "It has peen the custom of almost all authors, When treating of inflammations of the internal parts of the chest, to make a distinction betwixt pleurisy and pneumonia - it is 
seldom found but these two affections are united in the same degree. Besides they can scarce ever be distinguished by the symptoms, and to discriminate them would be of little value in practice, in as much as require precisely similar methods and cure."

From Sydenham to Laennac, according to conrad, (3), peripneumony was the term applied and during this tine there was no attempt at differentiation petween the two diseases, only to say that peripneumony was the term applied to the nore severe form and pleurisy to the less severe form of the disease. The disease as recognized today was made possible by Auenorugger (1761), and Laennac (1819), who clearly pointed out the percussion and auseultation signs found within the chest.

Howard, (1), related that Hathew Balllie (1793), called attention to the resemblance of the pneumonic lung to the Ilver (hepatization). Conrad, (3), says that Rokitansky, (1842), described the minute anatony of the disease and differentiated it into lobar and lobular varieties.

According to Howard, (1), Louls Pasteur in 1881, 1solatad the pneumococcus from the sputum and in 1884, Fraenkel determined that thig organism was the most frequent cause of pneumonia. About this same time Ruffer demonstrated a $G$ ram positive pneu mococcus isolated from an Egyptian mumn many thousand years empalmed, showing that the coccus was present many thousand yearg ago. Neufeld, in 1910, isolated pneumococci into four different groups which was later confirmed by many others.

Ancient Therapy.

As stated by Conrad, (3), Hippocrates treated the disease 
quite precisely. For the severe pain in the shoulder and arms, he bled the patient sometimes to the point of syncope. For the pain in the chest, he applied lionseed poultices and used cupping. If they had pain in the abdomen, or lower chest, he purged them withholding food. Up to 1871, bleeding was the principle method of treatment. Walshe, at this time, did not believe in the method so much, but the general opinion forced him to bleed his pneumonia patients. However, the amount of blood letting was a question and subject for debate. It seemed that in the beginning of the disease as much as 24-36 ounces of blood could be let three tines a day which seemed to be beneficial to the patient in the early stages of the diseage, but In the later stages more caution had to be taken. Snith, (4), states that during the first half of the ninw teenth century blood letting was a common practice. They found that the patient breathed easier and that the pulse lost its hard tense character. The "cupping" of the clot and the "buffy coat" were pointed to as being the urgency for the occasion. It was recored, in Berne in 1762, that ninty-ilve cases were treated by this maneuver with eighty-five deaths. Whereas, seventy seven cases were treated without bleeding and only ten were fatal. By the latter part of the ninteenth century bleeding in the early stages of pneumonia had lost its prominence as a therapeutic measure but the value in the late pleeding of some cases was advocated by many. They believed that cyanosis, signs of overdistention of the right side of the heart with epigastric pulsation, prominence of the juglar veins and a small and irregutar pulse were indications for venesection, and relief was generally 
Biven when gix to eight ounces of blood had peen withdrawn. According to Conrad, (3), at the close of the eighteenth century, DListers were commonly used. They were used on the Legs and arms with the idea of exciting the powers of the systern, therepy rendering admissable further oleedings. Alkalieg were also used. They delieved them to be efficient in rendering the olood less pDastic. They also knew that when hepatized lungs were placed in alkaline solutions that the lung tisgue softened, Alkalies used were bicarbonate of soda, potassium or ammonium soaps and also potassium or sodium sulphates. They also practiced purging pneumonia patients with the view in mind that they were lessening the congestion in the lungs and rendering the individual less likely to have bilious complications.

Calomel and optum were used elther separately or combined. Large doseg of calomel, one to five grains were used. Smith, (4), stateg that in 1850 Watson, Cameron and others used mer cury to the point of salivation. Doses ranging from fifty to sixty graing of calomel were given early in the disease belive Ing it to have a sedative action. Tartar emetic was used by some of the physiclans to the point of producing vomiting and as high as five to six stools daily. Tonics were given chiefly in the form of wines and barks.

Conrad, (3), relates that about 1859 chloroform inhalations were used chiefly by Varentrapp and Wucherer. Sixty minums of the drug was placed on cotton and the patient was allowed to inhale this every ten to fifteen minutes, not enough to produce unconsciousness. Smith, (4), states that about this same time 
Clemens, of Frankfort, used chloroform Inhalations degcribing Its sedative action on the nervous system and its anticoagulating effect on the blood. He also described its results to its powerful antigermicidal effect on the organism in the lung.

About 1861 Flint began useing quinine in fifteen grain doses daily and concluded that it exerted a marked curstive effect on the disease. In 1881 Smith (4) advised twenty to thirty grain doseg daily claiming that in these doses it aborted the disease. In $1895 \mathrm{Kerr}$ advocated the use of creosote in large doses. He considered it the nearest approach to a specific in that it was eliminated largely by the lungs. He used it in ten minum doses every two hours. Robinson recommended the value of creosote inhalations not only for benefit of the patient but a.lso for prophylaxis of attendants. Dr. Robert Liegal in 1898 wote concerning the use of sodium sallcylate in large doses such as one hundred twenty grains per day. He treated seventy two cases ranging in age from sixteen to seventy four years without a single death and found that from the second day on the fever gradually disappeared and symptoms abated. He considered this form of treatment to have a specific effect such as it exhibits in rheumatic fever. He assuned that it acted upon the mucous memorane increasing its secretion and thereby throwing off the exudate, as croupous membrane is thrown off from the larynx.

I might state that oxygen therapy is by no means a modern contribution to the treataent of pneuronia. Accoraing to Smith, (4), It was introduced by him into this country in 1860. He considered it an important aid in the treatnent and a definite 
physiological aid to the patient if used early in the disease. The most comon error, he believed, was the delay of its use until the patient becane cyanotic and the ald hunger became marked. He believed that the use of oxygen would tend to ward off such symptons if used early in the disease.

Conrad, (3), related that at the beginning of the twentieth century there came the genersi opinion that drugs seemed not to have much influence on the course of the disease and a frantic search for specifics for the disease gtarted. Many claimed. many different drugs to be specifics. Among ther was Schwartz Who claimed that lodine was a specific. Other drugs which held the reign for short times were soda benzoate, salicylates, ergot, creosote carbonate, and a variety of others. About 1910 serums and vacines came into prominence.

\section{Prophylaxis.}

In recent years prophylaxis has come to be regarded as a primary therapeutic measure in treatment of many diseases. So it is with pneumonia that prophylaxis is an important measure in prevention and spread of the disease. According to Austrian, (5), auto-inoculation seldom is the cause in a case of pneumonia. He says that special research carried on by the Rockefeller inatitute shows the disease to be more comonly due to infection by contact either direct or indirect. Types I and II, which are responsible for over 60 per cent of the pneumonia cases, are never harbored in the normal buccal cavity but are found only in patients suffering from the disease or in the sputum of convalescents (convalescent carriers), or persons who have 
acquired the organisms by being in close contact with pneumonia patients (healthy carriers).

Every case of pneumonia is a posgible source of infection, and thus measures as are necessary to prevent gpread of other contageous diseases should be used here. The patient should be isolated, all eating utensils, clothing, linens, etc., should be sterlilzed by bolling before removal from the room. All excreta should be properly sterilized before being disposed of. A 5\% phenol solution is a good antiseptic for this purpose. The room should be cleansed daily so as to prevent spread by dust and after convalescence the room should be cleansed preferably with hot soda water and allowed fresh air and sunshine. Attendants and members of the family should by all means carry out prophlactic hygiene and pay egpecial attention to the throat. Also, it is advisable that they wear a gauze mouth and throat guard. Known carriers should be instructed as to dangers of sneezing and coughing in the presence of others. Howard, (1), stateg that a considerable proportion of cases are due to autoinoculation as a result of the lowering of resistance from exposure to cold, physical fatigue, trauma or presence of cardioe vascular disease or to increased virulence of the organism. With reference to apecific vaccination, Howard, (1), states that as early as 1913 Lister working among miners in south Africa vaccinated a large group of workerg with large doses of killed cultures at seven day intervals and proved to his satisfaction that immunity was established for a period of one year. Later Cecil and Austin working at Camp Upton inoculated more than 12,000 soldiers. Cultures were made by growing in $0.5 \%$ glucose broth, 
and killed by heating to $53^{\circ} \mathrm{C}$. for half an hour. Types I,II, and III pneumococci were used, and the inoculations made at 37 day intervalg. They obtained fewer $100 a l$ and toxic reactions following the use of repeated small injections. Total dosage was six to nine billion of Types $I$ and II, and four to six bilIlon of Type III. Over a period of ten weeks observation not a single man developed pneumonia which had been vaccinated whereas in a control group of 20,000 men there were 26 cases of pneumonia due to types I, II and III pneumococcus.

Cecil (6), states that prevention of pneumonia means the prevention of the milder respiratory infections. Nearly every case in the Bellevue Hospital gives a history of a previous sore throat, cold or influenza. He is convinced that with respect to the common cold that autogenous vaccines every week or ten days throughout the spring and winter are of great value in their prevention. He advocates the use of a polyvalent vaccine for patients who have had several attacks of pneumonia ana live In constant dread of still another attack. Pnounococcus vavine is indicated also in elderly patients who suffer every winter from bronchitis. It is a prophylactic measure against the more serious complications.

General Management.

As in many other diseases rest is a primary and essential factor in the treatment of pneumonia. As clearly pointed out by Howard, (1), a sultaole bed should be provided with a firm spring mattress so that the patient acquires the greatest re laxation. An adjustaole headrest is an advantage in that the patient can be placed in the semi-Fowler position so that the 
greatest relief from dyspnea can be obtained. Tro frequent examination of the chest should oe refrained from, visitors should be 1 imited to numbers and visits made short. According to Austrian, (5), daily examinations of the chest, especially the posterior lobes, should de made, because only in this way may the extent of the pulmonic lesion be noted and the chance for overlooking a pleural exudate is minimized. No unnecessary expoaure or exertion should be allowed. The patient should not be allowed to sit up at any time.

The majority of men advocate treating the pneumonia patient by allowing plenty of fresh air. A temperature of $60^{\circ} \mathrm{F}$. is not unharmful and seems to have a distinct advantage in comforting the patient. Austrlan, (5), says that the windows should be open and whenever conditions allow the patient should be wheeled on to a protected porch. Fresh air makes respiration easier, stimulateg the circulation and quiets the nervous system, promotes appetite and, according to statistics, lowers the mortality of the disease. Horrard, (1) claims that comon senge should be used in allowing the patient fresh air. Undue exposure in stormy weather is absolutely harmful and if the patient prefers being In a warmer room he should be so allowed. K.G. Freeman is a strong advocate of open air treatment and claims it increases the chllds' vitality so that the disease runs a shorter course, and that the mortality rate is lowered. According to R.N. Willson of Philadelphia; "The resoiration becomes easier, the heart action less lapored, sleep comes with less effort ana food is taizen with sone relish when the patient is removed even from the well aired room to the outdoor air. Both the cerebral symp- 
tons (delirium) and the occasional distressing intestinal paresis, seem less likely to occur and ane more easily controlled under the outdoor regime."

It is generally agreed, that the diet should consist of plenty of liquid, meat and vegetaple proths, cereals, egg nogs, soft eggs, custards and jellies. These foods furnish a high percentage of calories and are easily digestaple. To increase the calorie content, lactose or glucose may be added to the 11quids. Austrian, (5), relates that studies reported by Austrian indicate that in the usual diet of the pneumonia patient there is too little salt. He advocates giving the patient at least 10-25 grams of sodium chloride each day. A cpolous intake of water should be administered, at least three liters per day because of its effect to promote elimination.

Hydrotherapeutic measures should be taken. The patient should be bathed frequently with tepid waterand a brisk rub follow. This promotes circulation, increases blood pressure, stimulates the respiration and promotes elimination. Ice and cold spongeing are distinctly harmful and should be avolded. Pleurisy is such a frequent complication of pneumonia that its treatment really becomes a part of the treatment of the disease. The pain, which is severe, is usually relieved on rendering the chest imopile, and so it is that the physician first thinks of adhesive tape. According to Howard, (1), this is not a good measure since it interferes with chest expansion, promotes moxemia, interferes with chest examinations and may cause local skin infection. He advocates the use of lce bag or hot water bottle. According to Gordon, (7), the only object in applications to the chest is relief of pain or of an irritating 
cough. Ice sometimes works wonders. Strange to say, a hot water bottle or an electric pad may do just the sare, though neither has any effect on the progress of the disease. A Iinseed poultice may succeed where all of the others fall, or vica versa, and a mustard plastar has peen a great source of comfort. The use of diatherny has, with some, acquired some popularity.

Tympanites, which often accompanies pneumonia, is regarded by many as a serious prognostic sign. Gordon, (7), claims that its recognition, as a result of toxaemia and not as due to intestinal fermentation, suggests more active hydrotherapy and central nervous stinulation as well as the guarded use of pituitrin. According to Thomas, (9), meteorism is due to splanchnic paralysis and he also regards it as a grave symptom. The abdomen becomes distended, drum-like and further increases the already lapored respiration. He advucates the use of surglcal pituitrin in doses of $\frac{1}{3}-1$ cc. Howard, (1), also regards the distengion as due to a paralysis of the intestinal musculature. He advocateg turpentine stupes; if/seen early, may relieve the patient. If seen late, 1 may be necessary to give the patient turpentine enema, and if all measurea fail he advocates use of pituitrin in I c.c. dose hypodernically.

Bleeding, although practiced by the ancients, still has many advocates. Austrian (5), belleves that it should be used in all cases where evidence of acute dilitation of the right side of the heart developes, and he advocates the bleeding of 250-500 c.c. of blood. Osler (2) says that in healthy, robust Individuals where the disease has a quick onset with high fever and other pronounced symptoms that early bleeding is of value. He definitely states that it is indicated in cases where dili- 
tation of the heart occurs. The amount depending on the effect.

\section{Narcotics.}

Opium or its derivatives have long been regarded as the most helpful drug in the treatment of this diseage, as regards relief from pain and promotion of rest. It is equally beneficial in slowing respiration and also in deepening it. Under opium, in medicinal doses, the minute yolume of inspired air is not diminished. Gordon, (7), says that the unfortunate (or fortunate) susceptibility of some people to the drug compels one to try various forms, and where morphia is not tolerated, Dover's powder, or pantopon may be. But in the majority of instances morphia hypodermically is the best form of administration.

Davis, ( () , made important obgervations on the treatment of pneumonia cases with roorphine. Older writers were of the opinion that morphine was harmful and only used codiene. Cecile and Cole are of the opinion that morphine should be used for the pain. Davis agrees with Cushny that in cases where the respIration is barely sufficient to aerate the blood, or where profuse espectoration is present, morphine is dangerous, because of its depressant action on the respiratory center, the tendency to abdominal distention, and to the relaxation of the bronchial musculature and thus danger of edema of the lung is increased.

He made obgervations on human beings, the greater number who were acutely ill with lobar pneumonia. "One hundred and seventy-three observations were made on thirty-three different cases of pneumonia. On these forty-three arterial punctures were made. Fifteen patients were studied in a body plethygmograph from fifty minutes to one and one half hours. An arterial 
puncture was done before and after each respiratory tracking was made. Morphine was given subcutaneously while the patient was in the plethy smograph and a second tracking was made from 15 - 30 minutes after the administration of the drug. The dose of morphine varied from $10-18 \mathrm{mgms}$. The resplratory movements of fifteen patients were studied in the plethysmograph before and after norphine administration. In all but one case there was a drop in rate. The average drop in fourteen cases was 4.1 to a minute. The greatest fall was from $42.5-34.4$. In one patient the rate increased. from $40-42$ per minute. His tidal air, however, fell from 244 to $186 \mathrm{c.c}$, and his minute volume from $9.78-7.81$ liters. His breathing indicated edena of the lungs and at the time of observation he was rapidly growing worse. His arterial saturation drooped from $85.9-84.7$ per cent after administration of morphine."

"The effect of morphine on the oxygen saturation of the arterial blood as observed in 16 patients out of 20 on whom oxygen analysis of the arterial blod were done before and after morphine, was a deopin the arterial saturation. The greatest drop was $21.3 \%$ and the average drop 5\%. Of the remaining 4 cases, 3 showed a slight rise in oxygen saturation after morphine. One of these three cases had severe pain, which was relieved by morphine. His tidal air increased from $412-438 \mathrm{c} . \mathrm{c}$. though his minute volume dropped from 13.35 - 10.96 1iters. In only 3 cases was the change in oxygen saturation great enough to be of gignificance. In one the saturation fell from 82.564.9. This was a man 63 years of age who had been gick for three days. He appeared cyanotic and dyspneic, signs of consolidation 
extended from the left apex to the Dase. At the left base were signs of fluid. Molst rales were present in both lungs. His wos blood culture positive for pneumococcus type III. In another case the saturation fell from $87.2-78.7$. This was in an obese woman of 50 years, who had a severe chill three days previously. The right middle and lower lobes were involved. Throughout both lungs bronchovesicular breathing and numerous rales were heard. She appeared cyanotic. Blood culture was positive for type II. The next day her arterial saturation was 93.2. Five days later she died." He concluded; "In most ceges of pneumonia the effect of morphine on the respiratory movements and on the arterial oxygen saturation is slight. Certainly the depression of respa iration which follows morphine administration is ordinarily not sufficient to contraindicate its use. The benefits which ray accue to the patient in the direction of relief from pain, reduction of metabolism and sleep, undoubtedly outweigh the possIble $i 11$ effects of a slight reduction in pulmonary ventilation and increase of anoxemia. Occasionally, however, morphine nay so diminish pulmonary ventilation as to result in serious oxygen want. This is liable to occur in patients in whon the pulmonary involvement is extensive and is accompanied by diffuse moisture, and in patients who are already suffering from severe mant. Because of the possiblilty of this type of reaction to it, morphine must always be used with caution and is best combined With oxygen therapy. When there is much pleuritic pain, the relief brought by morphine may 3.110 w the pulmonary ventilation to inerease and thus raise slightly the per cent saturation of the arterial blood."

Howard, (I), is emphatic in his belief that the best way 
to relieve pleural pain 1 s by administration of morphine ( 8 r $1 / 4)$, codein $\left(g r^{\frac{1}{3}}\right)$, heroin $(g r$ 1/12), or pantopon (minums 7 ) administered hypodermically every twelve hours.

\section{Digitalis}

Digitalis therapy has probably been argued more than any other measure in the therapy of pneumonia. Howard, (1), gtateg that it should not be used except when there is coexisting heart disease as auricular fibrillation, or where some other serious myocardial disease coexists with pneunonia. When given it should be given in full physological dosage so as to get the patient digitalized. This may be done by giving the patient 4 c.c. of the tincture every four hours until six doses have been given, or toxic symptoms of digitalig are brought on.

Niles and Wyckoff, (10), studied 835 cases at the Bellevue Hospital over a period of two years uselng a control group. They found the mortality to be $7-10 \%$ higher in the digitalized group. These caseg were studied as to weight, sex and age of patient. They concluded that, although they would like to study the effects of digitalis over a series of years, the committee were of the opinion, judging from effects thus far, that digitalig should not be used in lobar pneumonia patients. Stone, (11), studying a series of 1205 cases of pneumonia and 259 autopsies found that in the autopsies performed, the heart was normal in showe to 20.6 per cent, parenchymatous degeneration in 52.9 per cent, fatty degeneration in 11.7 per cent, leukocyte and round cell infiltration in 8.9 per cent, hyaline degeneration in 2.9 per cent. He believed digitalis therapy to be rational. If it was to be used he belleved it should be used early before the 
heart had become incompetent through dilitation or muscle degeneration with consequent exhaustion of its reserve toxicity.

Osler (2) advises that only in severe cases should digitalig be adminiatered early. It may then be given in the form of tincture (MXV) three or four times daily. If signs of cardiac weakness become manifest, injections of one of the digitalia prepsrations is indicated, Straphanthin ( $8 r$ 1/100) intramuscurly or intravenously. Austrian (5), has a similar view in that he believeg digitalls in small dosage should be administered early to all pneumonia patients so that if its indications arise a prompt effect can soon be obtained.

\section{St1mulants.}

Heart stimulants seem to be commonly employed and have a distinct indication in collapse due to circulatory failure. However in collapse without evidence of cardiac failure Gordon (7) feels that adrenalin and atropin hypodermically have the best chance of restoring vasomotor control. He believes strychnine has gone out of fashion but its use has alvays seemed rational on account of lts known effect upon the spinal centerg. Caffiene is undoubtedly a useful cardiac and a respiratory stimulant, but it has the disadvantage of keeping the patient awake. Austrian, (5), and usler, (2), both support the view that atropin is valuable and should be administered where there is evidence of pulmonary edema. Osler, (2), advocates also the use of strychnine because of its effect on the regpiratory center, also that it should be administered only over brief periods in full doses ( $g r 1 / 20)$ every 2 or 3 hours. 


\section{Glucose Therapy.}

In recent years, probably more research work has been carried on with glucose therapy in connection with a wide variety of diseases. So it is with pneumonia in which case glucose therapy has many sound advocates. Litchfield (12) relates that three-fifths of the pody welght is water and the body needs it in order to maintain the volume of blood necessary for the mechanical efficiency of the circulatory apparatus, to carry nourishment to the cells, to carry away soluble waste products of metabolism and to maintain the proper solutions and osmotic conditions essential to normal cell life. When water is taken from blood it is taken from tissues thereby infringing on vital procesges of the cells. In pneumonia, besides dehydration we have to deal with intoxication and nitrogen starvation. Hypertonic glucose is a remedy because it is non-toxic, it is quickly utilized by the organism, it is the best sparer of nitrogen, it is a stimulant to the mechanism of cell metabolism and it is eagily obtainable and easily prepared.

For clinical work $250 \mathrm{c} .0$. of a 25 per cent solution ia tine type used by Litchileld, (12), He uses double distilled sterile water with glucose dissolved, and allows it to flow freely into the vein. Temperature of the solution should be $100^{\circ} \mathrm{F}$. He has given as high as $1700 \mathrm{c} . \mathrm{c}$. takping eleven hours without any evidence of glycosuria. He claims that often in glucose adminigtration the patient becomes brighter and less toxic. The respand Iration becomes slower, the pulse becomes stronger $\Lambda$ slower, and the blood pressure rises. The pulse amplitude is increased, fh tongue becomes moist, petient asks for water and food, the kidneys and bowels becone nore active. If the patient was regtlesg 
or delirious he becomes quiet and goes to sleep, often while the injection is being given. He advocates the giving of glucoge at intervals of $8-12-18$ and 24 hours as the case nay be. Baum (13) says that the chief problem is how to give a therapeutic amount without taxing a heart muscle which is already overburdened. He advocates the use of small, frequent doses, useing an inftial dose of 50 c.c. of a 25 per cent solution given with a large syringe and a 22 guage intravenous needle, taking 30 minutes to adminlster it. This proceedure is repeated at aoproximately four hour intervals during the next four or five days and nights, gradually increasing the amount and dilution until the patient is getting 200 c.c. of a twelve and onehalf per cent solution at four hour intervals. He gays that sclerosis often occurs at the site of injection and thus new veins have to be used.

Baum (13) explains the probable mode of action of glucose physiologically in that the muscle tisgues, including the heart and liver have the power of converting glucoge to glucogen and visa versa as the body may need it. Glucose is already partially oxidized and readily asgimilable, but nust be flrst converted to glycogen before it can be utilized by the tissues. In this process of furnishing energy for various decompositions and bodily activities, it is reduced to alcohol, carbon dioxide, fatty acids and water. Tissues which are deprived of oxygen live much longer when supplied by glucose. Thus in a patient suffering with pneumonia, havling much of the lung generating space filled with exudate, the blood stream filled with toxic products which interferes with oxygen combining power, and a 
sluggish heart also deprived of oxygen and glucose, glucose probaply gives to the tigsues that which will tide them over the crisis.

Baum states, "In health, it is posaible for the amimal body to synthesize glycogen from carbohydrates, proteins, and to a slight degree from fats. It is also possible for the animal organism to synthesize glycogen from various amino acics as Glycocoll, alanine, aspartic acid, glutamic acid and tyrosine. This synthesis is, at least, in part, performed by the liver after the deaminization of the amino acids in the intestinal wall before being carried to the liver in the portal circulation. Here, again oxygen is a prerequisite for this trangformation. It is logical to asgume, that because of the anoxemia of pneumonia, the stored glycogen is goon depleted and unable to be replenished by the liver and muscle tissues. Another possible assumption is that, the liver, in endeavoring to free the organism of toxemia, puts its function of detoxification to the fore at the expense of tis glycogenic function. Koster and others have shown that the administration of glucose causes marked changes in the Kupfer cells of the liver and attribute the beneficlal results from glucose to the stimulation of the reticuloendothelial system." He explains the clearing of the cyanosis on the oasis of liberation of carbon dioxide from the metabolism of glucose which acts as a respiratory stimulus. Algo, that the kidney function is improved probably by glucose metabolisin, the aste productg are better prepared for excretion oy the kidneys, or that the output is due to a higher intake of liquid. Hac Lachlan, Kastin and Lynch, (14), advise giving 400-600 
grams of dextrose by mouth per day. They dissolve 200 grams of dextrose (Dextrose powder - Corn Productg Co.) in 1000 c.c. of water to mich is added the juice of two or three lemons. The liter thus contains about 800 calories and they try to have the patient arink two or three liters every twenty four hours, thus providing 1600 to 2400 calories. When the case is narkedly toxic, or will not take enough by nouth, they advige givfling $200 \mathrm{c.c}$. Of a 25 per cent solution intravenously takping one half hour for injection. By this method 800 to 1200 calor ies are provided the patient in 24 hours. A $50 \%$ solution however may be uged. The adequate dogage by nouth is 400 grans, by vein 200 grans and the closer one gets to 2400 calories per day the better. They advocate that subcutaneous administration is of value where absolutely needed but that it disturos the patient too much and by recturn they do not get enough calories.

\section{Drugs}

Ilany drugs have held the reign as a specific for the treatment of pneumonia in the gearch for an ideal specific. Austrian (5), relates that gulacol carbonate, camphor, creosote, quinine, the iodides, antimony, the salicylates, digitalis, iron and numerous other preparations each have been advocated. wone of these have had a specific effect but some may have a curative value. Bridges, (15), agcribes good success with the uge of guiacol carbonate as a routine measure. He advocates usłing gulacol carbonate grains5, quinine grains 2 , and strychnin sulphate gr $1 / 30$ every four hours.

According to Howard, (1), quinine has been used for over fifty years. It was used originally as a tonic, later as an antipyretic and more recently a a specific. In 1911, Morgenroth 
and Levy discovered ethylhydrocuprein (optochin), a quinine derivative. It was found to exert a specific influence on the pneumococcus in animal experiments. Shortly after Morgenroth made his publication of his discovery, the drug was placed on the market under the trade name optochin. When it was first used, many patients became deaf, timitis, ambliopic, etc, due to the fact that its proper dosage could not be determined. Prior to 1916, the upper limit of dosage seemed to be 1.5 grams per 24 hours in an average gized man.

Moore and Chesney, (16), found, from the literature they collected,787 cases treated with optochin with a mortality of 12.96 per cent, afigure which is encouragling. It seems logical that if optochin can be adninistered in such dosage as to produce within the human organism a condition whereby pneumococci are destroyed in situ or, at least prevented from local or general migration, and from establishment of their growth in previously uninfected regions, it seems dxikely that marked therapeutic results can be expected from its use.

Wright was the first to show that serum from human patients receiving the drug by mouth destroyed pneumococel in the test tube. Hoore and Chesney, (16), showed that this action from a single dose lasts but a few hours. The organisms nust recelve frequent adequate dosages in order to be af bestrefted. They found that the best bacteriocidal action was gotten by givfing 0.022 to 0.0268 grams per Kilo. of body weight in twenty four hours.

A review of the literature in which cases have been treated seems to give disappointing results in that the mortality is not seriously affected. It may be due to the organisms beconing e. fast, but since the serum of patients rectivingfotochin in therm 
apeutic dosage tends to inhibit or in sone cases destroy the pneumococcus, it tends to throw suspicion on this theory. Another theory is that the organisms in the blood stream are usually destroyed or inhibited in twenty four hours at most, but that the exudate in the lungs guard the organisms so that the drug does not get to them. The bacteriocidal actions of the drug in the blood serum seems to be very transient. Also, it is a dangerous drug in that toxic symptoms such as mentioned above may occur and even permanent impaiment of vision.

Murphy, (17), has recently puolished an article in which he attributes marked results with the use of intravenous colIosol lodine. He uses $10 \mathrm{c.c}$. of a 1 per cent solution which he repeats if necessary at the end of one or two days. He has only used it on a very limited number of cases in conjunction with the usual routine, symptomatic treatment. He finds that frequently the general toxemia is overcome within twenty four to forty eight hours after the initial dose hag been given. Also he attributes marked results with its use in the treatment of post-operative pneumonia.

In reviewing the literature I found that there are still many who routinely advige the giving of large doses of salicylates. Swensen, (18), advises giving full doses of salicylates, usually starting with acetyl salicylic acid, if the patient is able to take it orally. In an adult he used about fifteen grains every two or three hours. If he is unable to take the salicylate by nouth, sodium salicylate is given intravenously or in two to four gran doses rectally, repeating as often as indicated. Along with this type of treatnent it is generally agreed that 
alkalies should be used to maintain the alkalinity of the blood. Larder, (19), advises that there is nothing better for this purpose than sodiurn citrate or acetate, 20 grains given every two to four hours as needed. Since the effect is evanescent he meintains that a dose or two should be given during the night, other alkalies have been used and still are being used guch as bicarm bonate of soda and potassium citrate.

\section{Oxygen Therapy.}

Probably one of the best measures to offer comfort to the patient is the administration of oxygen. As stated previougly, its use was first introduced into this country in 1860. According to collins, (20), the first article published on the administration of oxygen was in 1887 by George E. Holtzapplie. The patient was given oxygen by potig manufactured ath bedside by usqing black oxide of manganese and chlorate of potash. The man's breathing decreased from 80 to 60 and cyanosis diseppeared. The man finally recovered.

According to Cuthbertson, (21), the blood in normal persons is about $95 \%$ saturated. If this gets down to 80 or below very prominent symptons arise as are seen in pneumonia patients such as cyanosis, delirium, abnormal irritation of medullary centers and further impairment of the myocardium. Many theories as to the production of cyanosis have been expounded. Cuthbertson believes that the most logical theory is that it is due to a layer of fluid between the air space and alveolar wall or to a functional disturbance of the alveolar epithelium. He believes oxygen is absolutely essential since there is no apm preciable diminution in the oxygen capacity or in the power of the blood to become saturated. Also that oxygen is not merely 
palliative but curative, and it must be adminlstered at once If it is to break the vicious circle before the onset of untoward symptoms.

Oxygen is transmitted by the blood inflemoination with hemoglobin called oxyhemoglobin and is dissociated from the hemoglooin as is needed by the tisgueg in their metabolismas the oxyhemoglobin loses its oxygen it loses its bright red color and becomes increasingly darker. It is the reduced hemoglobin Which gives the blood its pecullar color in pneumonia and accounts for the cyanosis seen in most cases of pneumonia. When there ox

is a large amount of reduced hemoglobin in the blood we are in the habit of speaking of the as anoxemia. There is a definite amount of oxygen that a hemoglobin molecule can take up and this is in definite proportion to the iron content. Fhe percentage saturation is of great value in pneumonia. If an artery is punf atured we can determine the oxygen content and the maximum amount of oxygen this amount of blood wil take up. The ratio between the first and the second figure is known as the percentage saturation of the hemoglobin. Normally the oxygen content is 19 volumes per cent so that the per cent saturation is 95 per cent. It is known that anoxemia may get marked in pneumonia and it has been shown that it bears a relationship to the mortality. A hemoglobin percentage saturation less than 70 per cent indicates a grave prognosis.

Guedel, Shiner and Cunningham, (22), say that for each degree of fever reaction there is an increage of 7 per cent in the metabolism so that the tissues are burned much faster. This puts a strain on the cardio vascular system by calling for an increase 
of oxygen to the tissues to support the increased metabolism and more food to carry on the work.

Quoting Guedel, Shiner and Cunningham:- "As engorgement progresses to consolidation the pulmonary absorption area may be decreased to the extent that sufficient oxygen for the support of the increased metabolism cannot be delivered into the. blood strean from an ordinary atmospheric environment. The patlent early developes a pleuritis, the pain of which, through the physical and mental excitement that it provokes, further increases the body metabolism. The patient manifegts the anxious restlessness of air hunger early, with the pleuritic pain in hibiting a fuller respiratory excursion to supply the additional air that is needed. This restlessness is another potent factor in increasing pody metabolism. Thus, with the arterial oxygen low and the metabolic oxygen high, nature reacts by incresing the cardiac output to compensate for the increasing oxygen unsaturation of the blood and body tissues."

"Physiology depends largely on oxygen for 1ts support. Any oxygen deprivation interferes with the complete combustion of the body wastes with the nevitable regultant dysfunction of cell acidosis. An acidotic cell cannot utilize the food that is carried to it."

"Dextrose furnishes largely the power by which muscie contracts and by which the body carries on. In the execution of this power, through chemical combinations or reactions dextrose ia converted into lactic acid. In the conversion of dextrose to lactic acid oxygen is not required. However, whereas probably five partg of dextrose are thus converted into lactic acid through muscle work, four parts of this lactic acid are reconverted into 
dextrose, to be used again in the repetition of the same pros cess. This reconversion is notably an oxidation reaction. The remaining fifth part of lactic acid is further converted by oxidation into carpon dioxide and water, in which form it is eliminated. Any interference with the reconversion of lactic acid into dextrose 111 necessarily rob the body tissues of their sustenance. In pneumonia, such interference is in proportion to the degree of anoxemia present. Also, the same oxygen depletion, by its failure to support the reconversion of lactic acid into dextrose, will leave deposited within the cell proportionately more waste lactic acid, which cannot be eliminated. Thus in prolonged partial anoxemia a vicious circle is formed. Assinilation of foods is inhibited pecause of cell acidosis, and cell acidosis cannot be relieved without oxygen. There is an ever increasing denand for oxygen with a progressively decreasing oxygen supply. Therefore nature continues to inpose more work on the heart in an effort to provide a compensatory Increase of blood to the cell. It must be remembered, the heart muscle, which is called on to do more work is also guffering as are the other tissues. If the antibody defense is raised to sufficlent power to neutralize the toxins of the invading pneumococcl before the heart must collapge, recovery is most agsured. In pneumonia the immediate problem is the heart. The general problem is the maintainence of physiologic function." By elevating the partial pressure of oxygen in the atmosphere we increase the rate of absorption through the alveolar epithelium. Too many errors are made by administering oxygen too late. Early application is advised shat is as soon as the respiratory rate can be lowered the patient beare to be Iess 
restless and more comfortable. It is easier to maintain a normal physiologic state than it is to retrieve it when it is lowered by intoxication and malnutrition.

The difuaion rate depends on the partial presgure of gases on opposite gides of the membrane and on the permeability of that membrane. A 20 per cent oxygen in atmospheric pressure is adequate to neintain ample diffusion through the normal alveolar membrane. In pneumonia the inflammatory engorgenent and exudate renders a much larger area less permeable than does the actual consolidation so it becomes necessary to increase the atmospheric oxygen pressure to maintin normal difusion.

A dosage of 30 to 50 per cent is adequate to eliminate the anoxemia factor. This should be given 39 soon as specified previously and bept up until well after the crigis when all symptons of anoxenis are abolished. The exact dosage is regulated by the symptons. One nay adopt the slogan; "Keep the finger-nails pink."

The patient should be made to understand it is only a therapeutic measure and not a last resort, as the public are of the opinion that it is the last resort to prevent death. quoting Guedel, Shiner and Cunningham, (22), "oxygen therapy in pneumonia to the abolition of anoxemia accomplishes the following, It provides a higher oxygen saturation of the blood and thus lesseng the heart load. It eupports the functions of waste conbustion and cell nutrition. It supports the aerooic stage of muscle work (reconversion of lactic acid into glucose) and thus conserves food resources. Finally the cell having less lactic acid thrust on it and havking oxygen support for the combustion 
of that which it must eliminate, is kept in a more nearly normal physiologic state. The same is true of the heart. Its fatigue products are better carried off, its cells are better nourished, and its work is less. Under ample oxygen support the pneumonic heart, as well as the entire human organisn, carries on better and longer than would be pogsible under partial anoxemia. A few hours or days added to the resistance period contributes that much more tine for completion of the antibody defense. Finally, the intelifgent administration of oxygen in pneumonia is physiologically sound. Although it cannot constitute an entire treatment, it is an important therapeutic measure."

Collins, (20), treated nineteen cases with the oxysen teat. The time at which this treatment was administered he did not say, however he noted that in every case except one the cyanosis was relieved and the patient became less restless and breathed more easily.

Personally, I am acquainted with one case in which the oxygen teat wag used with marked succesg in comforting the patient as shown by less rapld and labored respirations, less restlessness and disappearance of cyanosis. This was a woman, aged 31 years, White, married, Who entered the University Hoapital February 11, 1932 complaining of pain in lower abdonen, dificult, rapid respirations, and productive cough. At this time she was seven months pregnant. She gave a history of havfing had grippe, accompanied by cough, three weeks previous to entrance. Three days previous to entrance, her respirations became rapid and painful. Her history was essentially negative except that the patient had not menstruated since June 6, 1931. Family history was negative. 
Temperature on entrance was $105^{\circ}$, pulse 140 and respirations 48. Face was flushed and lips cyanotic. Examination bf chest revealed dulinese on percussion over entire right lung and over left base. Bronchial breathing, and five roler were heard at the end of inspiration over the same area. Abdominal examination revealed that she was probably seven months pregnant. Urine analysis at this time was negative. Blood count was 4,800,000 red cells, 23,800 white cells. Differential count showed 87 per cent polyneuclear leukocytes and $13 \%$ lymphocytes. Typeing at this time revealed a Type I pneumococcus. The blood culture was negative throughout the course of the disease. She ran an remittant type of temperature, rigling as high as $105^{\circ}$ during the day and as low as $99^{\circ}$ in early morning. On Feb. 13, 1932 she delivered a baby girl (premature) with but a few pains (precipitate). thonly medication used up to this time ras codiene, grain one-half. Following delivery her symptons became more marked and she became markedly cyanotic, coughing almost continuously. On February 14, 1932 she ras placed in an oxygen tent. She immediately became much more comfortable, less restless and pyenosis disappeared, and breathing less rapid and labored. Oxygen 38 to 42 per cent was used. The minute she was taken out of the tent she would becone markedly uncomfortale, restless and cyanotic. Breathing would become more rapid and Labored.

The only other therapeutic measures used were gymptomatic. Norphine was necessary at timesto relieve pain. Surgical pituitrin was adrinistered once for distention. At one time proulse became rapid, of poor quality and irregular so that digalen 1 c.c. was administered hypodermically. On February 16, 1932, in the afternoon, the patient had her crisis but oxygen was continued 
until the following alay. The patient's temperature then gradually flattened out and she recovered. She was discharged from the hospital on fiarch 13, 1932 apparently well. One case is really of no value on which to base conclusions but its marked effect in conforting this petient has led me to believe that it is definitely palliative although probably not curative.

The subcutaneoug use of axygen has been used by a few. Crespigny, (23), treated two cases with apparently marked results. In both cases, the injection was made into the subcutaneous tissue of the axilla and enough introduced to raise an emphysematous area two times the size of the palm. The cyanosis disappeared rapidiy, the normal pink color appeared and the patient was markedly less restless and nore comfortable.

Diathermy .

Diatherny has been used by some with apparently marked results. Others absolutely are opposed to its use. Probably its therapeutic value lies in the intelligence with which it is administered. Clement, (24), says that pneumonia is one of the most aatiafactory conditions to treat with diathermy. The object is to rapidy allay the distressing symptoms as of course it is with all other therapeutic measures. After reviewing the cases Which he presents, it seeas that possibly diathermy shortened the course of the disease, in that the courae was only three to four days for those treated. He used anterior and posterior electrodes, useing a block of tin posteriorly and a nesh anteriorly. His dosage usually ranged from 1400 milliamperes on the first day, increasing to 2000 to 2500 milliamperes on the second day for the same length of time, and for each successive day as 
long as the syptoms did not change.

Seypold, (25), believes that the earlier the diagnosis of pneumonia is made, the sooner diatherny is applied, the petter are the results. He believes diathermy apparently gives the best results, if given early, or during the stage of congestion. The physiological action of diathermy on inflammatory areas being that of hyperenia. Diathermy in his estimation is an absorbent, a dissolvent, a decongestant, an analgesic, a nutrient and a bacteriacidal agent. The local effect therefore being an active hyperemia and softening of the infiltration by the physiological action of heat. Absorption of toxic productg takeg place through this decongesting process. The capiltaries and lymph channels surrounding the congested area are dilated, vasomotor constriction lessened, Which has a tendency to increase the flow of blood. This causes the surrounding edema to subside. In pneumonia it is assured that early diatherny has a tendency to keep it in a stage of congestion, which prevents this morbid process from progressing to red and gray hepatization, and in many cases appears or makes one believe that the pneumonia has aborted. At least the temperature subsides and the chest findings are improved. At the first sign of any chest congestion, he therefore advocates the use of diathermy. As to systemic effects of diathermy, there is at times an intense perspiratton, which acts as an excellant form of elimination, relieving the cardiovascular and renal systems.

"The influence of diathermy on the clinical picture is at times remarkable. Thoracic pain is lessened, rapid shallow breathIng changes into slower deeper breathing, unproductive cough changes into a productive one, the pulse tone improves, meteor 
ism is lessened, that symptomatic relief is ootained is unques tionable."

He uges the high voltage taps on the nachine and the usual H. As around 2.000 for grownups. This depends upon the pat lent, type of machine, size of electrodes and the like. The frequency of his machine is 800,000 . The duration of the treatment is from twenty to forty minutes. These are given every eight hours or oftener if the case warrents it. Ordinarily they are given twice, or in milder cases once in twenty four hours. Compressed Air.

Joannides, (26), in a series of experiments with dogs found that the lung expanded when air pressure (intrabronchial) became $25-30 \mathrm{~mm}$. At between 60-100 mm. mercury there developed interstitial emphysema, pneumothorax, pneumoperitoneum and air embolism. He also found that by severing the heart fram connection with the pulmonary vessels and introduceing air at a pressure just to distend the alveoli that air escaped to the capillaries and that finally all the olood was forced from the capillaries and they pecame filled with air. When the lungs become Immobilized by external compression or drowning with exudate the lung loses its elasticity and little or no air enters or leaves the lung. The result is the heart suffers fram overwork and asphyxial charges and the patient collapses because of circulatory decomm pensation. The pneumonia patient thus needs a supply of oxygen and elimination of waste products as a result of asphyxia.

In experimenting with dogs he ilinds that when an artificial pneumothorax is developed the blood pressure in the femoral artery shows a gradual diminution in the respiratory waves unti 1 tinally there is a pulse pressure oI zero. At this point the 
heart shows a delinite prady cardia and soon stops beating. If at any time artilicial respiration is instituted the ampiitude of the respiratory waves becone normal and the animal may be kept alive as long as desired. It is quite necessary that there be some olocking of the outflow of air so as to raise the intrapulmonic pressure to petween $20-35 \mathrm{~mm}$. of mercury. He finds that in his experiments where he vorks under artilicial?that it is necegsary to use oxygen and that it is unneoessary and expen give and that in compressed air there is sutilicient oxygen to take care of axphyxia and that by blocking the outflow to raise the intrathoracic pressure the sufficient expansion and contraction reinforces the circulation. Theoretically then by applying this nethod to pneumonia cages we can visualize nuw the alveolar walls would be stretched and contracted, how air would find its way into the blood by being of higher pressure in the lung and also how this would do away with anoxeria and reinforce the circulation. He has experimented with dogs with apparently good resultg, the heart and circulation improved, and that pulmonic and consolidated, dark colored lungs when subjected to increased Intrapulmonic air pressure either inside or outside of the body became crepitating and pinkish again. Theortically this work is fine but in the future maybe sone practical applications will be had on which to base sone conclusions.

\section{Artificial Pneumothorax}

Recently, Coghlan, (27), found that during an investigation into lobar pneumonia he discovered that the induction of artiflcial pneumothorax had a favourable influence on the progress of the disease.

The induction of the artificial pneumothorax, acoording to 
Coghlan, has the advantage of separating the inflaned pleural surfaces thereby relieving pain and allowing of easy respirations, putting the inflamed lung at rest, and limiting the flow of blood through the pneumonic lung thereby dimintshing anoxemia and interiering with the passage of toxing into the general circulation.

He reported $s i x$ cages on which the method was used. There was one fatality which he attributed to error of judgement in a difficult gituation and lack of knowledge of the technique, owing to inexperience, rather than to a defect in the method of treatment.

Erom these six cases he drew several conclusions. The first was that the induction initiated events very similar to those Which normally occur in the disease. The second was that the control of the pneumonic process is at first only temporary, persisting merely as long as air remains in the pleural cavity. Since the absorptive capacity of the pleura in this disease is abnormally high the time taken to absorb the air is a matter of hours only, after which the pneumonic process becomes reestablished at its orlginal level. By adequate refills, he found that the return of the disease can be forestalled, and when the artificial pneumothorax control has been maintained for a sufficient length of time ( 48 hours apeared to be sufficient) the pathological procesg is definitely brought to an end, the air can be absorbed with - out any tendancy to relapse, and convalescence proceeds normally. Quoting Coghlan:- "A striking feature of 11 the cases was the rapidity of the onset of the artificial crisis; profuse presperation set in almost as the pneumothorax needle was withdrawn, and cyanosis and dyspnea were relieved in about $15-30$ minutes at most, causing corresponding supjective improvement. The fall of temperature was well established in two to three hours, and the 
patient lost that appearance of acute distregs characterigtic of pneuronia."

There are some dangers in the process. The contamination it wex of the pleura in introducking the needle which 1 if woutd occur would cause a mixed infection which would be markedly serious. Therefore, at each injection new cites are chosen for the introduction of the needle.

In Coghlan's serkes, not one developed pleural infection. Cardiac collapse at time of the crisis was thought to be a secondary danger. However, in this instance, where the crisis developes several days sooner the heart is better prepared to meet the crigis and thus probably there is less danger. A definite crisis, however, is to be avolded by only minimal refills at the time perspiration commences and phenacitin, aspirin or Dovers' powders used to help keep up the perspiration so that the fever falls more by lysis and thus, there is less strain placed on the pulmonary circulation and, at the sane time, a progressive detoxlcation will be accomplished.

Coghlan advises the following routine proceedure:- "(1) PreIiminary medication one hour pefore induction with morphine gr $1 / 4$ (2) Thorough 1ocal anesthesia with novacain down to and including the parietal pleura (3) Very thorough asepsis auring induction (4) A preliminary fill of $400-600 \mathrm{cocm}$. of air, run in very slowly during the negative phase of the pregsure swing cycle, and with the needle clipped off during the high positive phases. (5) A second fill 12 hours later of $300-500 \mathrm{c.cm}$ of air. (6) If the pneumonic process is not completely controlled, a third fill of $100-150 \mathrm{com}$ of air may be given in another 12 or 18 hours. (7) Simultareous exhibition of a suitable diaphoretic and of Felton's serum in 
appropriate cases at the discretion of the operator. (8) Owing to the very poofuse perspiration, the comfort of the patient is much enchanced by warm gponging p.r.n. and nursing between blankets. (9) In cases where it is deemed inadvisable to provoke deferescence by crisis, and gradual fall by lysis is aimed at, three fills of $100-150 \mathrm{c}$. cm. at intervals of six hours might be given and further treatment judged by results."

\section{Serum Therapy}

Since the veginning of the twentieth century, it has been proven that certain elements such as opsonins, agglutins, precipitins etc. act as antibactericidal agents. Thus the pneumococcus has been one of those organisms on which much work has been done to develope these elements. According to Howard, (1), the primary Work in this direction was done in Germany. However Cole In America took up the suggestion and found that he was successful in manizing horses againgt types I and II pneumococci but not type III or IV. The method of immunizing the horse was by daily injections of dead pneumococci of a specitic type for at least seven injections. This set up an immunization in the horse, the attempt being made to get the serum of such strength that 0.2 c.c. Will protect mich against at least 0.1 . c. of a culture Which is of such virulence that $0.000001 \mathrm{c.c}$. Of an 18 hour broth culture will kill a mouse of $20 \mathrm{gm}$. weight within forty eight hours. The horse is then bled and the serum is separated from the clot and placed in bottles.

In usping the serum, one must keep in mind the fact that the Garlier it is given the better are its' therapeutic effect. Wany think that after the third day of the disease that it is of little value. Thus, a search has been made for a quicker vay of typing 
the patient than the mouge injection method which requires at leat 24 hours for good results. Therefore, it seems that there probably are only a very few cases in which the serun can be used to advantage, wing to the fact that many cases are not seen before at least the second day and also the delay due to typing. If the serum is used, cole believes, first seeing it the patient is sensitive to the serum by injection into the conjunctival sac of a few drops of the serum or the adminkstration of a few aropo intradernally, and watch for a reaction as evidenced oy hyperemia. The patient should also be questioned in regard to asthma, hay fever and usticania. If the patient is sensitive 5 c.c. of the serum may be injected slowly subcutaneously to render desensitive ation, waiting one half hour before adninistration of the dosage. the patient is then-given $100 \mathrm{c.c}$. Intravenously by gravity method every 48 hours until crisis occurs. In case of an aphylactic shock adrenalin should always be at hand for injection.

In reviewing the literature I find the results with the type I antipneumococcus serum gtriking in that nearly all authors write that it lowers the mortality anywhere from 5 to 30 per cent. The results with type II are not so striking. The usefulness of this serum seems to be rather limited to hospital practice pecauseof its bulk, its technique of administration and the protein reactions. Brown treated 22 cases, using antipneumococcus serum accord: ing to the above described technique, 14 of type I in which he had two deaths and 8 of type II in which he had 1 death. This is only a small series of cases but the results are very gimilar to findings in the larger series. The noted effects were that, symptomatically, the change is very striking, from a marked distressed condition to a much more comfortable condition. The period of 
toxicity is greatly reduced. Natural sleep returns more quickly as does appetite. Convalescence is nore rapid. The temperature usually drops rather abruptly following the use of serum.

Cruikshank, (29), finds that the quickest method of typeing is to injedt an initial dose of polyvalent I and I antipneumococcus serum. In six to eight hours a little olood is taken from the ear and tested for pregence of agglutnins. If agglutinins I are found the type is said to be II, and visa versa, since the agglutning are neutralized by the infecting organisms.

According to Howard, (1), Huntoonj in 1921 developed a polyvalent serur containing antibodies of types I, II and III. According to Cecil, (6), this serum is a water soluble extract of immune bodies taken from astipneumococcus horse serum. It contains the antioodies for types I, II, and II but not in concentrated form. Its disadvantares are that it does not have adequate potency and tends to produce sharp chills when given intravenously. It has been practically discarded.

The most recent effort to refine and concentrate antpneumococcus serum has been done by Loyd Felton. The serun, according to cruikshank, (29), is made by injecting a horge with killed virulent ogranians and then bled. The serun is allowed to separate otf and sodium phosphate is added and incubated at $37^{\circ} \mathrm{C}$. until a percipitate forms. The percipitate is dialyzed in water for $5-7$ days and the oontents of the sac is reised to a $\mathrm{PH}$ of 4.6 where another percipitate forms and is removed. The supernatent fluid 1s diluted 4-5 times. There is an elinination of the albumin faction which is so responsible for anaphylactic reactions. This sera is rich in opsoning and agglutnins and is antibactericidal not antitoxic and acts directly on organisms makeing them sus- 
ceptable to phagocytosis. This serum contains, on an average, 2000 units againgt type I and $1000-2000$ units against type II. Fleming, (30), says the method of administration may be either intrarascular, subcutaneous or intravenous. The intravenous method is more commonty employed since the antidodies of the horse serum are precipltated out and are thus less likely to produce shock. The serum is heated to $100^{\circ} \mathrm{F}$. before administration. Before administration, a small amount is instilled in the left? conjunctival aac and if the \$lightest redress occurrs the serum is contraindicated until desensitization of the patient is done. If the patient gives a history of asthra, hay fever, urticania or has had previous serum treatments it is absolutely contraindicated. The serum is injected into the anticupital vein takeing at least 10 minutes for the first c.c. and five minutes for the rest of the dose. The doctor should keep his finger on the pulge during the entire proceedure, as any change in the quality or rate of the pulse indicates a reaction. The dasage given is 10 c.c. Which can be repeated every 8 hours as evidenced by the condition of the patient. Repeating of the dose is indicated if the potient has a temperature beyond $102^{\circ} \mathrm{F}$. or signs of toxemia as evidenced by deliriun, exhaustion, incontinence etc.

Fleming's, (30), view, with which serum is used, is to ward off a septicemia and maintain a sterile blood, not to overcome the prinary focus in the lung as this will usually take care of itself.

Cowan and Harrington, (31), treated 57 cases of Lobar pneumonia with Felton's serum with a mortality of 10.3 per cent in contrest to their old series of 856 cases treated without serum With a mortality of 18.4 per cent. Quoting them "Eelton's serum 
is effective with types I and II infections alone. It has no effect on other infections. It seems clear that lobar pneumonia as recognized clinically, is due to a pheumococcal infection, and that more than half of the cases are due to infection by types I or II. The occurpnce of pneumonia in an adult is, we think, an indication to exhibit Felton's serum at once, and to continue its administration until the patient is better, or bacteriological investigation shows that type I or II is not the causal organiom in the particular case."

Finland and SutIiff, (32), recomend 100,000 units given within the first 24 hours. They report treatment of 59 cases at the Boston City Hospital. Twenty-seven cases were treated with sera and given large doses early in the disease. Indications of improvement were duration of disease, course of bacteremia and presence or absence of pulmonary extensions. Results showed that marked improvement resulted where serum was given early in the disease and in high dosage whereas if given in the first $24-30$ hours seven of the treated cases extended over a period of only three days as marked by the absence of temperature. However, if given late in the disease less value was attached to its usefulness. They found the sera to be of marked value poth in preventing and elininating bacteremia. All cases haveing a bacterenia and treated by sera showed no poitive blood culture anytine after administration of sera, add no case having a negative blood culture developed a positive.

Cecil, (6), remarks that it is interesting to note that monkeys can be given classical lobar pneumonia by intra-tracheal injection of type I pneumococcus. As soon as the classical symptoms of pneumonia present themselves they administer Felton's 
serum and find that almost immedately the temperature begins to fall and symptoms begin to disappear whereas the control group of monkeys die.

About 500 patients are recelved into the medical wards of the Bellvue hospital each year and they give each patient a number, the odd numbers receive the serum and the even ones do not. The patients are akked if they ever had asthma, hay fever, or urticara and a skin test or ophthalmic test is done. If all is negative, 5 c.c. of Felton's serum are given at once, intravenously, watching the patient closely. If there are no symotoms of anaphylaxis, the patient is given 50 to $75 \mathrm{c.c}$. on the first day. The subsequent day the dosage is governed by the reaction of the patient. Usually the temperature and other symptoms have subsided somewhat and 15 to $20 \mathrm{ccc}$. are given on the second day. Out of 44 cases receiving serum 10 to $12 \%$ showed serum sickness which came on 1 to 2 weeks after injection. In 153 treated cases of type I pneumonia, there was a mortality of 20.6 per cent. In type II, the results were not so good, 41.5 per cent mortality for treated and 54.5 per cent in the untreated series. In type III, 40 per cent for treated and 28.6 per cent for untreated. In type IV, serum appeared to be of benefit in that there was a mortality of 28.2 per cent for treated cases whereas there was a mortality of 38.3 per cent for untreated cases. The death rate, for 441 treated cases, was 30 per cent whereas for 444 untreated there was 39.2 per cent. Cec11, (6) believes that individuals, under 40 years of age, should recelve pelton's serum before taking time to receive laboratory data as it takes too long. Two thiras of these patients will be benerited because types I and II occur about that often under that age. All patients over 40 years 
should have their sputum typed before any serum is given as about two thirds of these cases are of type III or IV, and since there is no sera for these groups Felton's is useless.

Baldwin, (33), firmly believes that there are obvious advantages of the concentrate prepared according to Felton over whole serum. The factor of concentration, expressed in terms of units, is very helpful in fixing the dose and affords greater facility in administration, owing to its smaller volume. The dosage varying from 5 to $30 \mathrm{c.c}$. per cose with the concentrate as opposed to 50 to $200 \mathrm{c.c}$. When whole serum is used. The disadvantageg, inherent in any modification of whole serum consisting principally In thermal or chill reactions, are beconing less pronounced. Less than 10 per cent of all injections are followed by chill reactions. On the other hand, serum sickness is largely eliminated, less than $25 \%$ of the cases havfing this complication, and when it does occur it is mild, causing only brief discomfort incomparable in severity With that produced by the use of the whole serum. 
Conclusions.

1. Proper management of the pneumonia case, and possible vacs cination in crowded districts, tends to restrict the incidence of pneumoria.

2. Proper management, especially in the form of nurging, is a valueble asset to the pneumonia patient.

3. The benefits which are derived from morphine, in the relief irom pain, reduction of metabolism, and sleep, far outweigh any 111 effects that may be derived fron it. Theretore, it should be used in pneumonia for these purposes when other measures fall.

4. Turpentine stupes or enena are valuable to remove distention but if these measures fail the use of surgical pituitrin is indicated.

5. Ir severe pneumonia cases, digitalis probably ahould be administered in small dosage so that if tts action is desired later in the disease less time will be required to obtain 1 ts physiological action. In legs severe caseg, it should not be used unless it becomes indicated later in the disease.

6. Bleeding, although practiced by the ancients, is probably sttll valuable in relieving distention of the right side of the heart late in the courge of the disease.

7. Adrenalin and atropin are probably the best cardiac stimulats in time of collapge.

8. Glucose is valuable in that it is a simple means of proviaing the patient with calories. By mouth is as valuable as by veln. If the patient cannot take it by mouth then it should be given intravenously.

9. There are no specific arugs used in the treatment of pneumonia 
but a few are valuable if properly employed.

10. Oxygen is of value as a paliative measure in relieving cyanosis and restlessness. The oxygen tent method, with $a$ saturation of at least $40 \%$, is probably the best method of edministration.

11. Diathermy has proved valuable in a few hands.

12. Theoretically, compressed air is of value.

13. Production of artificial pneunothorax seems to be a step forward in the treatment of pneumonia. However, it is only In its infancy and further tests will prove its efficiency.

14. Serum is highly useful in the treatment of types I and II infections but of no value in types III and IV. Best results are obtalned when used early in the disease and in high dosage. It prevents and eliminates bacteremia. There are many advantages of Felton's serum over whole serum. It is concentrated and thus requires less amount per dose. There is an elimination of the albumin fraction which is so responsible for anaphylactic reactions. 
I. Howard, Campbell P., Diagnosis and Treatment of Pneumonia, Oxford Monographs, VoI. 10, P.4-7, P 201-237, 1931.

II. Osler, W. and Mccrae, T.: Principles and Practice of Hedleine, lith Edition.

III. Conrad, A.A. : Nebraska M.J., P.53-57, Feb. 1931.

I V. Smith, Andre H.: Stedman's Twentieth Century Practice of 浩edicine, Vol. XVI, P. 1-139.

V. Austrian, Charles R. : Tice Practice of Medicine, Vo1.3, P. $1-80$.

VI. Cecil, Rusgell L. : The Prevention and Treatment of Pneumon1a, New York State J. Hed., 30, P. 210-214, Feb. 15, 1930.

VII.Gordon, Alvah Hovey: The Treatment of Pneumonia, Proceedings of The International Assembly of The Inter-State PostgradUate Medical Association of North America for 1930, P.196-201, 1931.

VIII. Davis, J.S.: The Effect of Horphine on The Resplration in Fneumonia, J. Clin. Investigation, 6, P. 187, 1928.

IX. Thonas, Roy, E.; Management of Lobar Pneumonia, South. H.J. Jan. 1931.

X. Niles, Welter L. and Wychoff, John : Studies Concerning Digitalis therapy in Lobar Pneumonia, Am. J. 趾. Sc., P. 348 , 1930.

XI. Stone, W.J.: The Heart Huscle Changes in Pneumonia with Remarks on Digltalis Therapy, Ar. J.M. Sc., 163, P.659, 1922.

XII. Litchfield, L. : Glucose Intravenously as a therapeutic Measure, J.A.M.A., 71, P. 503, 1918.

XIII. Baum, Eldon E. : The Treatment of Pneumonia with Special Reference to GIucose Therapy and Theorles as to Itg prob- 
able Action, J. Oklahoma H.A., 24, P. 373-376, Dec. 1931. XIV. Mac Lachlan, W.W., Dastiin, G.J., and Lynch, R.: The Use of Dextrose in Pneumonia, Am. J. H. Sc., 179, P. 93, 1930.

XV. Bridges, E. L. : Management of Lobar rneumonia, Nebraska H. I., 2, P. 254, 12 arch 1917.

XVI. Moore, H.F. and Chesney, A.R. : A Study of Ethylhydrocuprein (Optochin) in The Treatment of Acute Lobar Pneumonia, Arch. Int. Med., 19, P.611, 1917 .

XVII. Murphy, R.V. : A Preliminary on an Intravenous Treatnent of The Pneumonias, Irigh J.M. Sc., 6th series, P. 289321, July 1931.

XVIII. Stengen, S.A. : Further Observations on the treatinent of rneumonia, Nebreska M.J., 16, P. 468-472, Dec. 1931. XIX. Lander, W.T. : Lobar Pneumonia, J. South Carolina M.A., 27, P. 304-305, Dec. 1931.

XX. Collins, L.H. : Oxygen Tent, Pennsylvania H.J., 33, P. 135137. Dec. 1929.

XXI. Cuthbertoon, D.P. : Certain Biochemical Aspects of Lobar Ineumonia, Glasgow H. J., 115, P.64-67, Feb. 1931.

XXII. GuedeI, A.E., Shiner, N., and Cunningham, J.M., : Anoxemia in Pneumonia, J. A. H. A., 92, P. 1152-53, Apri1 6, 1929.

XXIII. Crespigny, F.C. : Subcutaneous Administration of oxygen, H.J. of Australia, 1, P. 781-782, June 8, 1929.

XXIV. Clement, G. : Diathermy in Pneumonia, Arch. Phys. Therapy, 10, P. 315-317, July 1929.

XXV. Seybold, N.J. : Pneumonia and Diathermy, An. J. Phys. Therapy, 8, P. 16-17, April 1931 . 
XXVI. Joannides, Minas: Insufflation of Compressed Air in The Treatment of Pneumonia, Arch. Int. Med., 47, P. 196-201, Fep. 1931.

XXVII. Coghlan, J.J. : Treatment of Acute Lobar Pneumonia by Artificial Pneumothorax, The Lancet, 222, P.13-17, Jan.2,1932. XXVIII. Brown, M.H. : The Treatnent of Pneumonia with Concent trated Serum, Canadian Public Health J. 22, P. 109-119, March 1931.

XXIX. Cruickshank, Robert : The Treatment of Lobar Pneumonia Dy Felton Serum, Glasgow M. J., 115, P. 59-63, Fed. 1931. XXX. Fleming, John B. : Administration of Felton's Serum, Glasgow M.J., 115, Feb. 1931.

XXXI. Cowan, J.M. and Harrington, A.W. : Felton's Artioneumococcus Serum, Glaggov M.J., 115, P. 49-53, Feb. 1931. XXXII. Sutliff, F.D. and Finland, MaxweII: Type I Lobar Pneumonia Treated With Concentrated Antibody (FeIton), J.A.M.A., 96, Р. 1465-1469, May 2, 1931.

XXXIII. Baldwin, Horace 5. : The Specifle Therapy of Pneumom coccus Type I and Type II Pneumonia, Am. J. H. Sc., 181, P. 788-796, June 1931.

XXXIV. Genevilischev, A.E. : ODservations Pertaining to The Application of Specific Antipneumococcal Serum in The Treat-

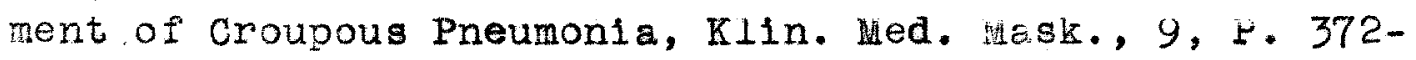
376, 1931. 


\section{$P E O E Y E D$ UNVERSTY OF NEERASKA

$$
\text { APR I: } 1932
$$$$
\text { TrFICE OF THE DEW }
$$ \\ COLLCE OF WEDONE}

